The Open Biomedical Engineering
Journal
CrossMark
Content list available at: www.benthamopen.com/TOBEJ/
DOI: $10.2174 / 1874120701812010135,2018,12,135-146$

RESEARCH ARTICLE

\title{
Motion Tracking for Quantitative and Qualitative Assessment of Upper Limb Movements Following Acromioclavicular Joint Ligament Reconstruction: A Pilot Study
}

Stefano Mazzoleni ${ }^{1,2, *}$, Elena Battini ${ }^{1,2}$, Matteo Galgani ${ }^{3,4}$, Miria Tenucci ${ }^{3,4}$, Paolo Dario ${ }^{1}$ and Giuseppe Calvosa ${ }^{3,4}$

${ }^{\prime}$ The BioRobotics Institute, Scuola Superiore Sant'Anna, Polo Sant'Anna Valdera, Viale R. Piaggio 34, 56025 Pontedera (Pisa), Italy

${ }^{2}$ Rehabilitation Bioengineering Laboratory, Auxilium Vitae Rehabilitation Center, Volterra, Italy

${ }^{3}$ U.O. Ortopedia e Traumatologia, Ospedale S. Maria Maddalena, Volterra, Italy

${ }^{4}$ Azienda USL Toscana, Nordovest, Italy

Received: August 1, 2018

Revised: November 19, 2018

Accepted: December 5, 2018

Abstract:

Background:

Technological tools as robotic devices and wearable sensors can provide accurate and repeatable measurements of physical variables (e.g., position, velocities, forces) which can be used for quantitative and qualitative assessment of movement analysis and upper limb motor performance.

\section{Objective:}

The study aims to propose a quantitative and qualitative assessment of upper limb motor performance by means of seven kinematic parameters recorded by a passive mechatronic device in patients who underwent a surgical procedure for ligament reconstruction following acromioclavicular joint dislocation.

\section{Method:}

Five patients (mean age: $40 \pm 12$ years) with acromioclavicular joint dislocation were enrolled.

A passive end-effector mechatronic device characterized by 7 degrees of freedom and designed for the assessment of upper limb motor performance - especially for measuring the hand position in three-dimensional space - was used.

The Constant-Murley score and seven kinematic parameters were used as clinical outcome measure and quantitative and qualitative assessment, respectively.

\section{Results:}

The preliminary results of this study show no significant differences between the impaired arm and unimpaired arm: the end-effector passive mechatronic device used in this study is able to provide an overall assessment of the upper limb motor performance following shoulder impairment.

\section{Conclusion:}

The motion tracker can be easily used as effective tool for quantitative and qualitative assessment of upper limb motor performance, even several years after the surgical operation.

* Address correspondence to this author at the The BioRobotics Institute, Scuola Superiore Sant'Anna, Polo Sant'Anna Valdera, Viale R. Piaggio, 34, 56025 Pontedera (Pisa), Italy; Tel: +39050883132; E-mail: stefano.mazzoleni@santannapisa.it 
Keywords: Orthopaedics, Rehabilitation, Upper limb, Assessment, Kinematics, Surgical operation.

\section{INTRODUCTION}

Motor disorders of the upper extremities following orthopaedic injuries often include joint and muscular stiffness, muscular weakness, disturbed muscle timing, reduced ability to selectively activate muscles and abnormal synergistic movement patterns on the arm and shoulder girdle $[1,2]$.

Approximately $9 \%$ of shoulder injuries involve damage to the Acromioclavicular Joint (ACJ) which are common in athletes, especially in contact sports or after a side fall while skiing, cycling or after motorbike accidents [3].

Rockwood and Green classified six types (e.g., form type I to type VI) of ACJ injuries based on the severity of the injury [4]: type I points out the less severe ACJ injury, whereas type VI, the most severe. Currently, the gold standard treatment for ACJ dislocation is still debated, especially for ACJ Rockwood types III through V [5]. The majority of these lesions can be successfully treated without surgery, in particular type I and II, on the other hand, surgical treatment is indicated for Rockwood type IV, V and VI injuries [6, 7]. The optimal choice for the treatment of type III is still debated [8]. Although previous meta-analyses have supported non operative treatment [9, 10], a recent study showed a significant functional outcome improvement after surgical treatment [11].

In fact during the last decades, a progression from conservative treatments has been observed (i.e., shoulder blockage for $3 / 4$ weeks), contributing to chronic shoulder functional impairment, to complex interventions aimed to achieve a coracoclavicular reduction and stabilization based on the use of tension bands, plates and artificial ligaments. As regards the latter approach, a study focused on the comparison between outcomes of two surgical procedures of coracoclavicular joint reconstruction showed better results when LARS artificial ligaments were used, in terms of stability and early shoulder mobilization [12].

The comparison of different orthopaedic surgical procedures is often presented without considering the effects of postoperative rehabilitation training. To date different assessment procedures are being used to evaluate postoperative and non-operative ACJ treatments [5, 9], however reliable quantitative outcome measures are still missing.

The assessment of residual motor functions and the effectiveness of therapeutic and surgical treatments are currently based on subjective observations performed by rehabilitation professionals (i.e., therapists, physiatrists) by means of clinical outcome measures.

Technological tools as robotic devices and wearable sensors can provide accurate and repeatable measurements of physical variables (e.g., position, velocities, forces) which can be used for quantitative and qualitative assessment of movement analysis and upper limb motor performance [13 - 16].

In fact, different methods for kinematic assessment of movement quality of upper limbs have been recently proposed [16 - 22]. Most of these methods, based on the analysis of kinematic parameters recorded during the robotassisted rehabilitation, have been developed and validated for neurological motor impairments (e.g., stroke). In particular, the following parameters are usually used to quantitatively and qualitatively evaluate the quality of upper limbs movements [13 - 21]: mean time of execution, mean distance, Speed Metric (SM), Final Mean Movement Deviation (FMMD), Number of Peaks in Speeds Profile (NSP), Normalized Reaching Speed (NRS) and Normalized jerk. These parameters are able to provide useful information on the upper limb movements in terms of accuracy, efficacy, smoothness, intra-limb coordination and workspace [20, 23].

The rehabilitation of the shoulder following an injury or a disease is crucial for the motor recovery of the Activities of Daily Living (ADLs) [24] as the hand function can not be achieved without a satisfactory control of proximal segments [25]: studies have shown that during grasping and reaching movements, the trajectories of shoulder, elbow and hand are strongly coupled [26].

The measurement of hand trajectories can provide relevant information for assessing upper limb motor performance. Human posture and movements can be measured by means of different types of sensors, as accelerometers, gyroscopes and flexible angular sensors (i.e., electrogoniometers) [27, 28]: the analysis of upper limb movements based on data recorded by such sensors can provide a quantitative assessment which can be used to evaluate the effectiveness of clinical treatments [29]. 
The objective of this study is to propose a quantitative and qualitative assessment of upper limb motor performance by means of a mechatronic device in patients who underwent a surgical procedure for ligament reconstruction following ACJ dislocation.

\section{METHODS}

\subsection{Participants}

Five patients (men, mean age: $40 \pm 12$ years, range: $20-51$ years) with acute Rockwood type III and V ACJ dislocation were evaluated retrospectively after ACJ ligament reconstruction. In three patients, the injury was caused by sport accidents, whereas in two patients, it was caused by an accidental event; two out of five patients underwent surgical treatment on the dominant side (both right) (Table 1). Surgery was performed between April 2011 and May 2012 with a mean Follow-Up (FU) time of 43.4 months (range: 36-55 months) and the mean time between the acute event and surgery was 3 days (range: 1-5 days). All procedures used in this study were in accordance with the Declaration of Helsinki.

Table 1. Patients characteristics. Legend: FU, follow-up; DS, Dominant Side; IS, Injured Side; /IS, Controlateral Side; CMS, Constant-Murley score.

\begin{tabular}{|c|c|c|c|c|c|c|c|c|c|}
\hline Patient ID & Age & Surgery date & $\begin{array}{c}\text { FU time } \\
\text { (months) }\end{array}$ & DS & IS & Injury cause & $\begin{array}{c}\text { Classification } \\
\text { (type) }\end{array}$ & $\begin{array}{c}\text { CS } \\
\text { IS }\end{array}$ & $\begin{array}{c}\text { CS } \\
\text { /IS }\end{array}$ \\
\hline 1 & 51 & $28 / 05 / 2012$ & 36 & R & L & accident & V & 95 & 100 \\
\hline 2 & 45 & $27 / 08 / 2010$ & 55 & R & R & sport & III & 98 & 100 \\
\hline 3 & 20 & $30 / 05 / 2012$ & 34 & L & R & sport & V & 92 & 100 \\
\hline 4 & 39 & $20 / 07 / 2011$ & 44 & R & R & accident & III & 98 & 100 \\
\hline 5 & 45 & $15 / 04 / 2011$ & 48 & R & L & sport & III & 100 & 100 \\
\hline
\end{tabular}

\subsection{Experimental Setup}

The ULTRA (Upper Limb TRAcker, Humanware Srl, Pisa, Italy) system, a passive end-effector mechatronic device was used in this study (Fig. 1). It is an articulated mechanical structure formed by 7 rotoidal joints corresponding to 7 Degrees Of Freedom (DOFs) divided as follows: 2 DOFs in correspondence of the shoulder joint, 1 DOF in correspondence of the elbow joint and 4 DOFs in correspondence of the wrist joint (Fig. 2).

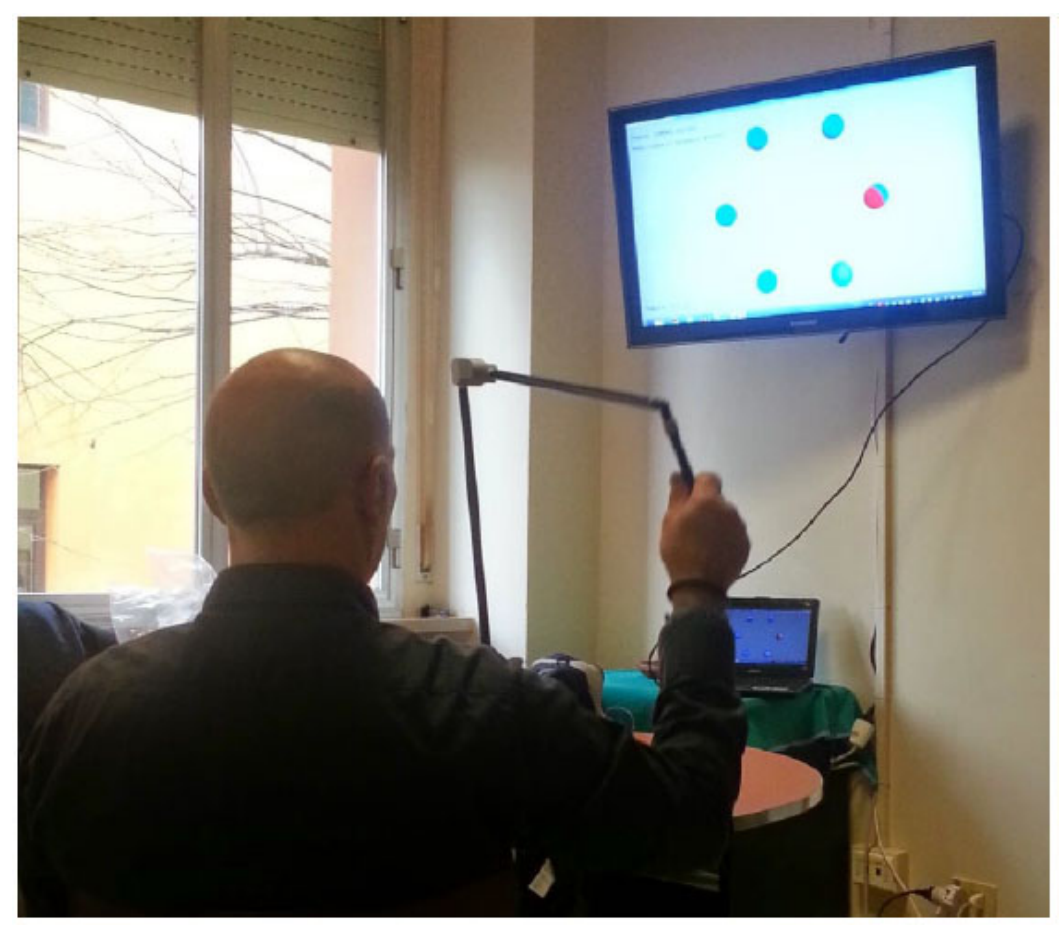

Fig. (1). A patient during the assessment procedure using the ULTRA system. 


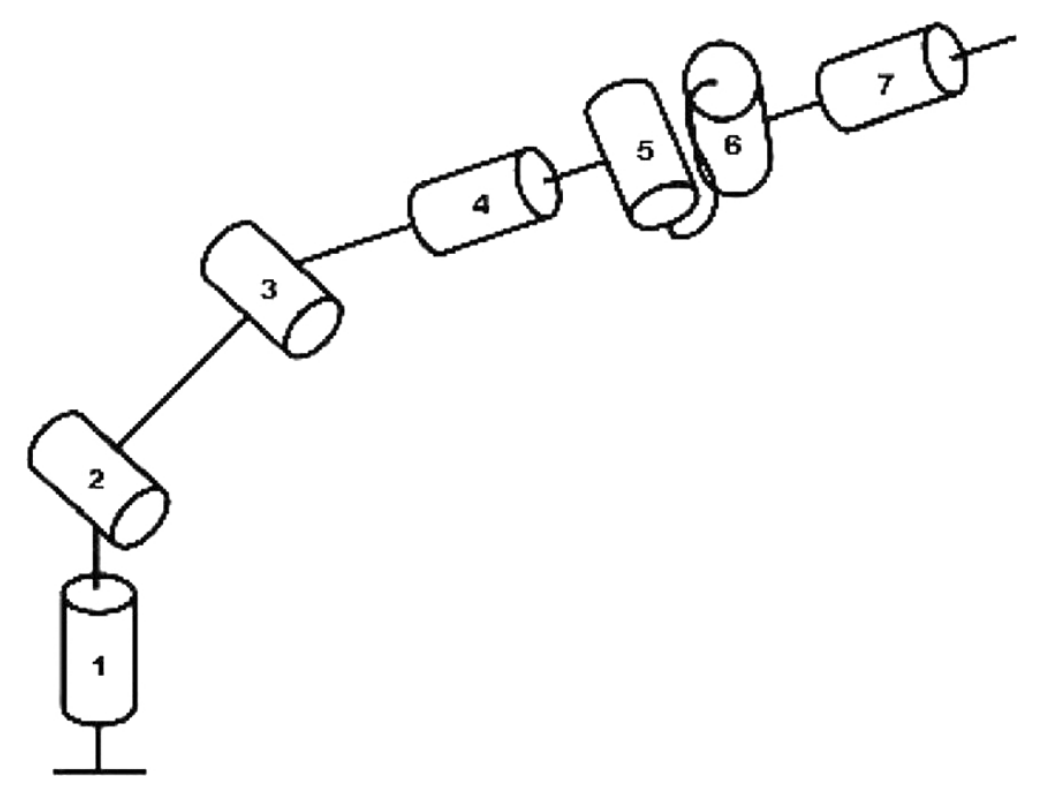

Fig. (2). Schematic representation of the kinematical structure of the ULTRA system.

The patient can perform upper limb movement by means of the ULTRA system: 2 DOFs on the shoulder joint allow to perform flexo/extension and abduction/adduction movements, the single DOF of the elbow permits to execute flexo/extension movement and the DOFs of the wrist allow to perform rotation, flexo/extension, abduction/adduction and prono/supination movements.

The ULTRA system is embedded with three rotary potentiometers providing the position of the end-effector.

The reference coordinate system is shown in Fig. (3) and the technical specifications of the ULTRA system are reported in Table 2.

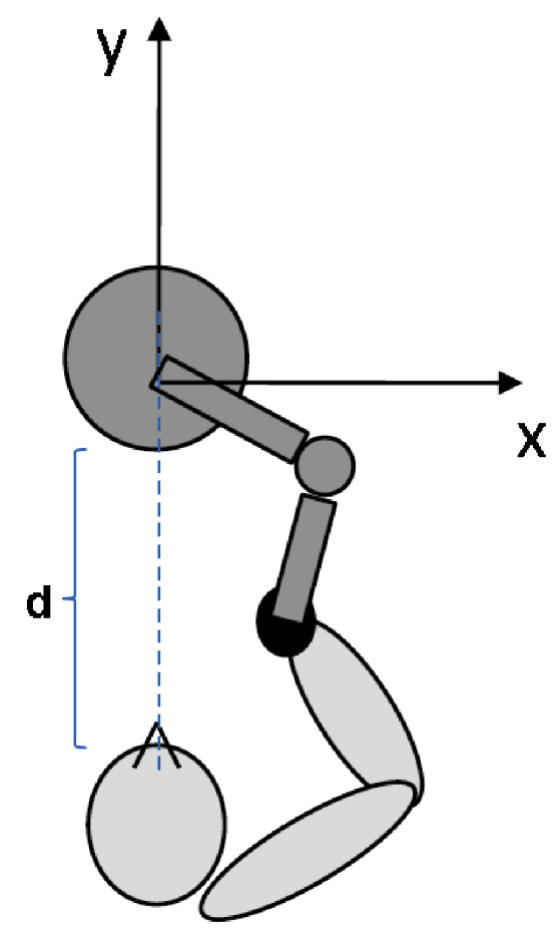

Fig. (3). The reference coordinate system $(\mathrm{d}=30 \mathrm{~cm})$. 
Table 2. The ULTRA system technical specifications.

\begin{tabular}{|c|c|}
\hline Resolution & $0.2 \mathrm{~mm}$ \\
\hline Linearity & $\pm 1 \%$ \\
\hline Workspace & $\varnothing 1700 \mathrm{~mm}$ \\
\hline Speed data transfer & $1.5 \mathrm{Mbit} / \mathrm{sec}$ \\
\hline Power supply & USB port \\
\hline Dimensions & $160 \times 195 \times 580 \mathrm{~mm}$ \\
\hline Weight & $1.5 \mathrm{~kg}$ \\
\hline Working temperature & $0^{\circ} \mathrm{C} \div+40^{\circ} \mathrm{C}$ \\
\hline Store temperature & $20^{\circ} \mathrm{C} \div+40^{\circ} \mathrm{C}$ \\
\hline Humidity & $0 \div 75 \%$ \\
\hline
\end{tabular}

The device is designed for the assessment of upper limb motor performance, especially for the measurement of the hand position in three-dimensional space: the motor performance assessment is based on reaching tasks, mainly focused on shoulder and elbow joints, which are performed by the patient by grabbing the end-effector.

The device provides visual and sound feedbacks and its workspace corresponds to the human upper limb workspace.

\subsection{Assessment of Motor Performance}

Each subject was asked to perform five reaching movements between consecutive targets (Fig. 4). As the real movement was carried out in a three-dimensional space and the rehabilitation scenario is in a bi-dimensional space, the movements along the depth were not considered. In fact, this study is mainly focused on the frontal (or coronal) plane where only the bi-dimensional components matter.

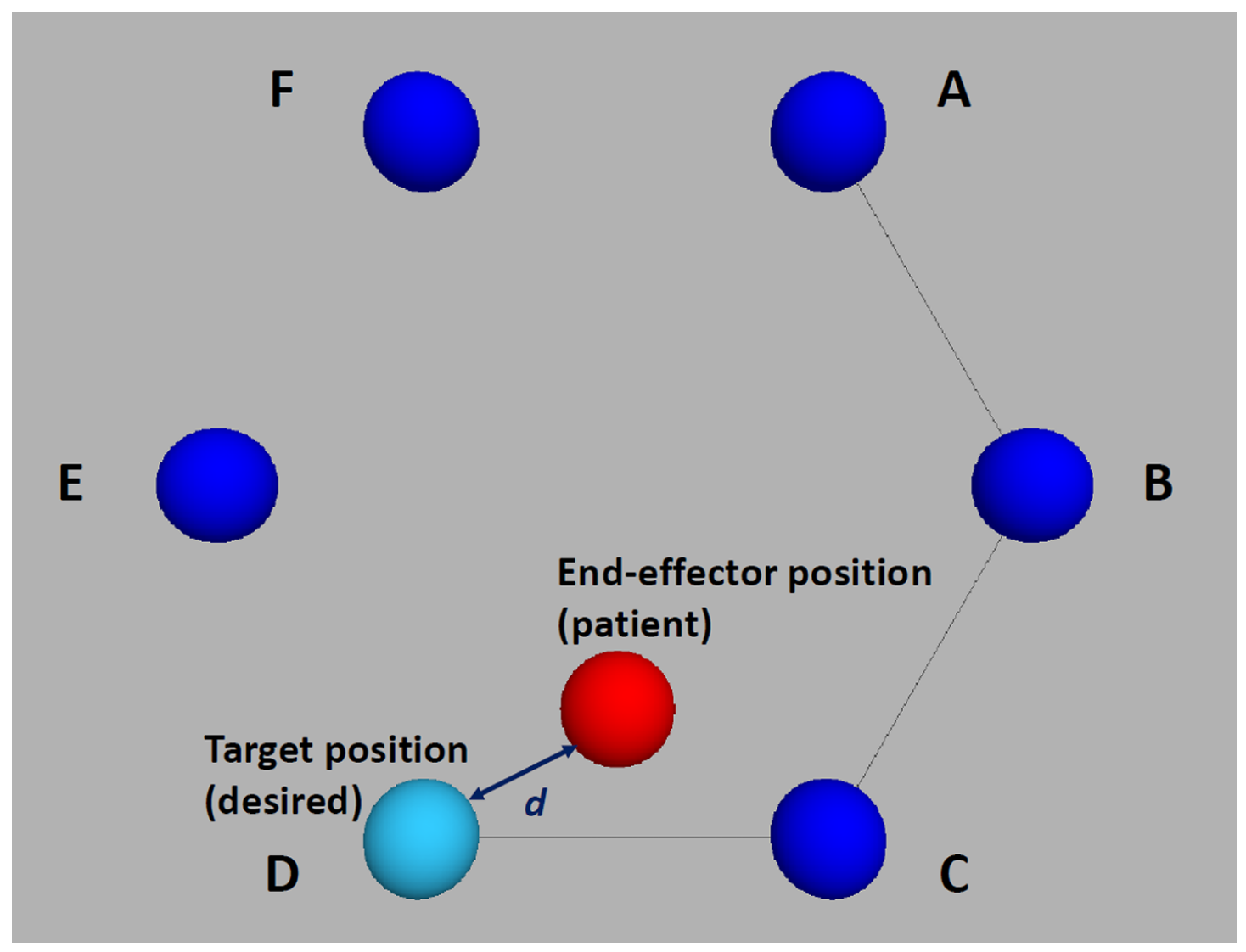

Fig. (4). The assessment scenario.

The position of the subject end-effector is shown on the monitor as a red circle: the target to be hit is represented by a light blue circle. Each of the six peripheral targets has to be hit clockwise: the ideal path to be followed is visually shown as a segment connecting two targets (i.e., previous and current target). When the end-effector position is close to 
the position of the target according to an adjustable precision threshold (here set at $10 \mathrm{~mm}$.), the target circle colour changes to green and the following target has to be hit.

Each subject performed initially three trials using the unimpaired arm and then three trials using the impaired arm. The resting period among trials is $\mathrm{t}=60$ seconds.

The coordinates $(\mathrm{x}, \mathrm{y})$ of the current position of the end-effector and the duration of each movement were recorded during each trial.

The recorded data were used to compute different parameters able to provide information on the end-effector kinematics and movement quality and duration.

\subsection{Clinical Outcome Measure}

The Constant-Murley Score (CMS) is a common clinical outcome measure used to evaluate the functionality of the upper limb following shoulder injuries. The CMS parameters determine the level of pain and the ability to carry out the activities of ADLs [31]. It is a scale based on a 100-point scoring system that provides a global score based on weighted measures of physical impairments in Range Of Motion (ROM) and strength, along with patient report pain and activity limitation [30 - 32]. The CMS is divided into four domains: pain (15 points), activities of daily living (20 points), strength (25 points) and range of motion (40 points): the higher the score, the higher the quality of the function.

It is accurately reproducible by different observers and is sufficiently sensitive to reveal even small changes in functions [33]. The method is easy to perform and requires a minimal amount of time for evaluation. Based on these features it was identified as a clinical outcome measure to be used in this pilot study. Table 1 shows the scores for both the Injured (IS) and controlateral (/IS) side.

\subsection{Kinematic Parameters}

Kinematic parameters recorded during the execution of upper limb movements may provide relevant objective information on the upper limb motor performance. The proposed kinematic parameters are computed both for the impaired and unimpaired upper limb in order to assess the motor recovery of the former after a surgical treatment by considering the values recorded on the latter as reference values for each subject.

The following features can be evaluated for the quantitative and qualitative assessment of upper limb motor performance: execution time, covered distance, movement speed, position error, movement smoothness [34]. Based on these categories, the following parameters were computed:

(1) Final Mean Time (FMT), defined as the mean time needed to reach each target.

(2) Mean Distance (MD), defined as follows:

$$
M D=\frac{\sum_{k=1}^{N}\left|d_{k}\right|}{N}
$$

where $d_{k}=\sqrt{\left(x_{d}-x\right)^{2}+\left(y_{d}-y\right)^{2}}$ is the distance between the desired $\left(x_{d}, y_{d}\right)$ and the actual position $(x, y)$ and $\mathrm{N}$ represents the number of samples in the movement recording.

(3) Speed Metric (SM) represents a normalized mean speed: it is computed as the ratio between the mean speed and the peak speed [35].

(4) Final Mean Movement Deviation (FMMD), defined as the final deviation between the desired target position and the actual position computed on each single target. It represents the movement accuracy. A low value of such parameter highlights a high accuracy.

(5) Number of Peaks in Speeds Profile (NSP), representing a measure of movement smoothness [36]. In an unperturbed reaching task, this value corresponds to 1 . A decreased value after a treatment compared to the initial value shows an improvement of the movement smoothness.

(6) Normalized Reaching Speed (NRS), computed as the ratio between the difference of peak speed and mean speed, and the peak speed: 


$$
N R S=\frac{v_{x y_{\max }}-\overline{v_{x y}}}{v_{x y_{\max }}}
$$

where $v_{x y_{\max }}$ represents the peak speed and $\overline{v_{x y}}$ is the mean speed. Low values of the parameter indicate smooth movements.

(7) Normalized jerk, defined as follows [37]:

$$
J=\sqrt[2]{0.5 * \int_{t_{\text {start }}}^{t_{\text {end }}} \operatorname{jerk}^{2}(t) d t * \frac{\text { duration }^{5}}{\text { lenght }^{2}}}
$$

This parameter is used to assess the smoothness of movement. It is based on the jerk analysis (i.e., the derivative of acceleration respect to time) and it is a normalized measure that is more susceptible to significant changes than other jerk definitions [35].

The difference between the operated and contralateral upper limb are computed and analysed by using the Wilcoxon signed rank test.

\section{RESULTS}

The aetiology of the injuries is represented by accidents due to fall from bicycles or motorbikes and traumas after sporting activities in relatively young subjects. All patients returned to their work, leisure and sports activity after surgery.

Table 1 shows CMS values after a surgical ligament reconstruction due to ACJ dislocation. Patient scores were excellent (average score 96.6/100), with no significant differences between operated and contralateral upper limb. In fact, the mean difference in the CMS scores between the operated and untreated shoulder is $3.40 \pm 3.13$ (range 0 -8). In particular, in two patients (ID 2 and ID 4) the injured side corresponds to the dominant side (i.e., right).

Fig. (5) and Table 3 shows the values of kinematic parameters expressed as mean values \pm standard deviation and the p-values of kinematic parameters, respectively.

\begin{tabular}{|c|c|c|c|c|c|c|}
\hline & IPA & $\mathbf{A B}$ & BC & CD & DE & $\mathbf{E F}$ \\
\hline FMMD & 0.34 & 0.84 & 0.48 & 0.34 & 0.77 & 0.26 \\
\hline FMT & 0.07 & 0.15 & 0.41 & 0.95 & 0.19 & 0.12 \\
\hline MD & $\mathrm{NC}$ & 0.19 & 0.45 & 0.79 & 0.38 & 0.19 \\
\hline NSP & $\mathrm{NC}$ & 0.53 & 0.19 & 0.22 & 0.25 & 0.63 \\
\hline SM & $\mathrm{NC}$ & 0.91 & 0.80 & 0.58 & 0.17 & 0.79 \\
\hline NRS & $\mathrm{NC}$ & 0.35 & 0.93 & 0.71 & 0.69 & 0.80 \\
\hline $\begin{array}{c}\text { Normalized } \\
\text { Jerk }\end{array}$ & $\mathrm{NC}$ & 0.37 & 0.36 & 0.89 & 0.06 & 0.49 \\
\hline
\end{tabular}

Table 3. The p-values of the kinematic parameters. Legend: NC: not computed.

As regards the movement kinematics, the differences between the impaired arm and unimpaired arm in terms of FMMD (Fig. 5a) and MD (Fig. 5c) are $0.73 \pm 2.37 \mathrm{~mm}$ and $-1.33 \pm 8.84 \mathrm{~mm}$, respectively.

The difference between the impaired arm and unimpaired arm in terms of FMT (Fig. 5b) values is equal to $-0.52 \pm$ 0.77 seconds.

As regards the movement smoothness assessed by NSP (Fig. 5d), SM (Fig. 5e), NRS (Fig. 5f) and normalized jerk (Fig. 6), the differences between the impaired arm and the unimpaired arm are $1.25 \pm 2.63,0.01 \pm 0.03,-0.29 \pm 1.39$ and $2.40 \pm 7.55$, respectively. 


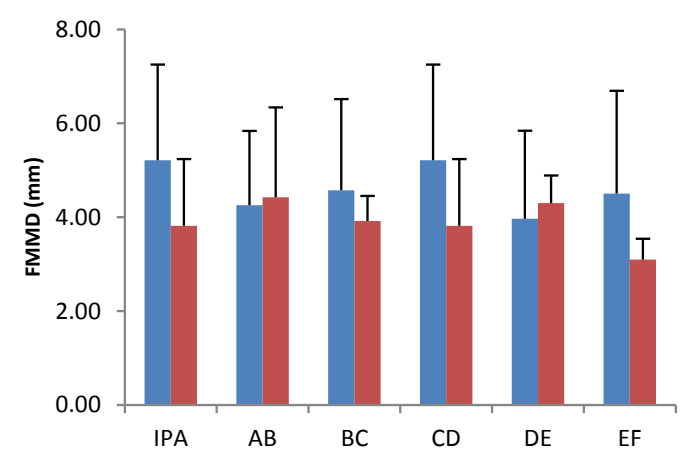

(a)

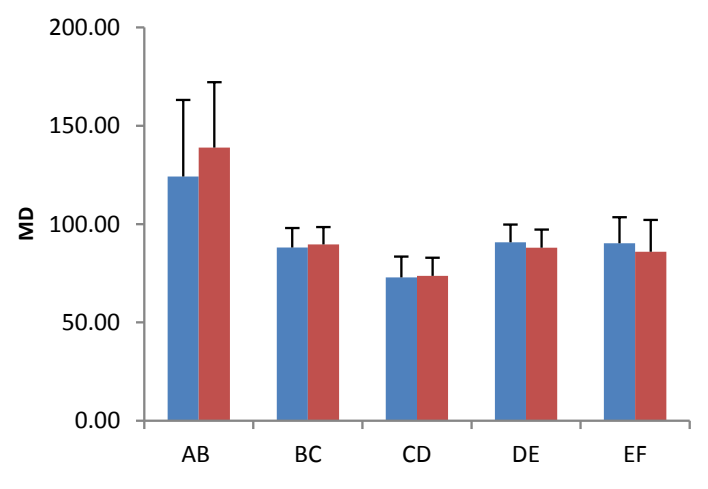

(c)

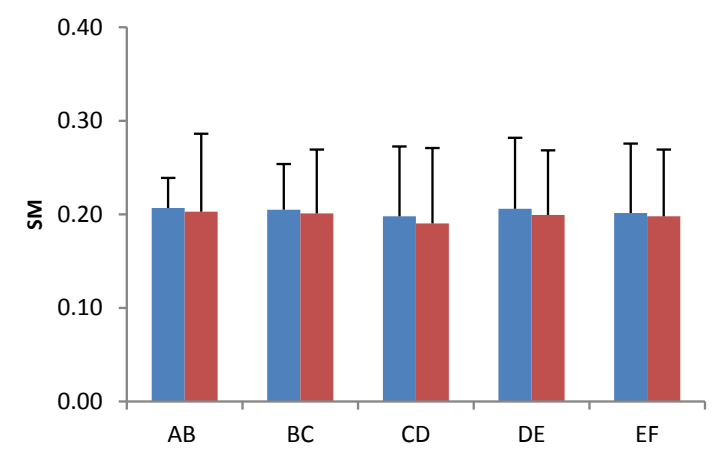

(e)

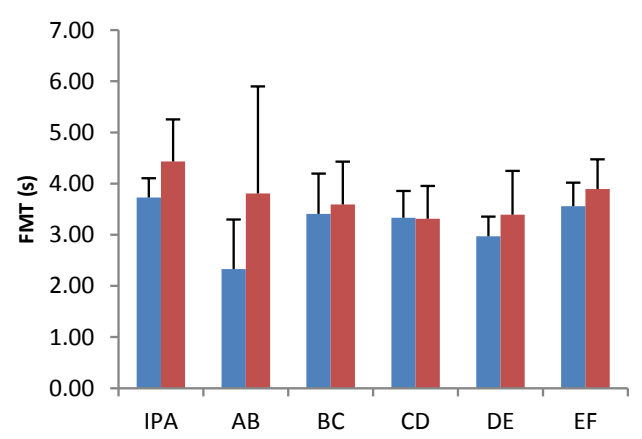

(b)

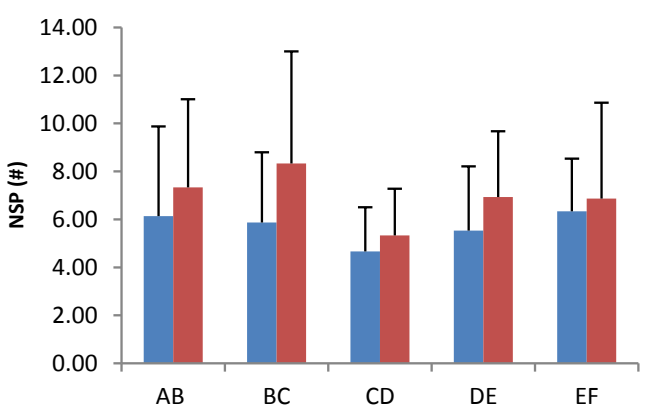

(d)

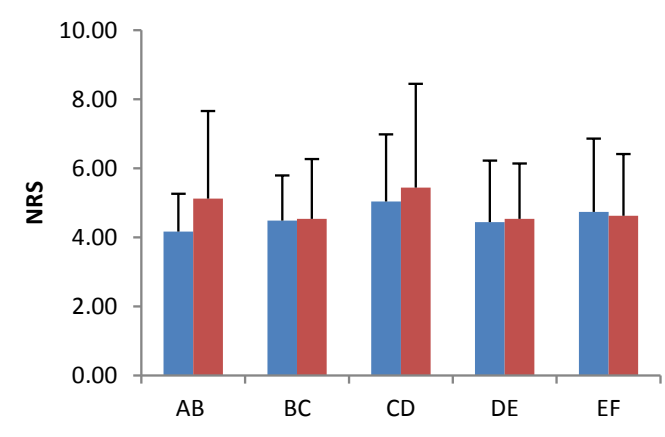

(f)

Fig. (5). FMMD (top left), FMT (top right), MD (middle left), NSP (middle right), SM (bottom left), NRS (bottom right). Values are expressed as mean \pm standard deviation. Legend. blue: impaired arm; red: unimpaired arm; IPA, initial point-target A. ${ }^{*} \mathrm{p}<0.05$.

\section{DISCUSSION}

This pilot study presents the application of an end-effector passive mechatronic device to upper limb motor performance assessment of patients who underwent a surgical procedure for ligament reconstruction following ACJ dislocation. 
The preliminary results presented in this study show the effectiveness of an end-effector passive mechatronic device able to provide an overall assessment of the upper limb motor performance.

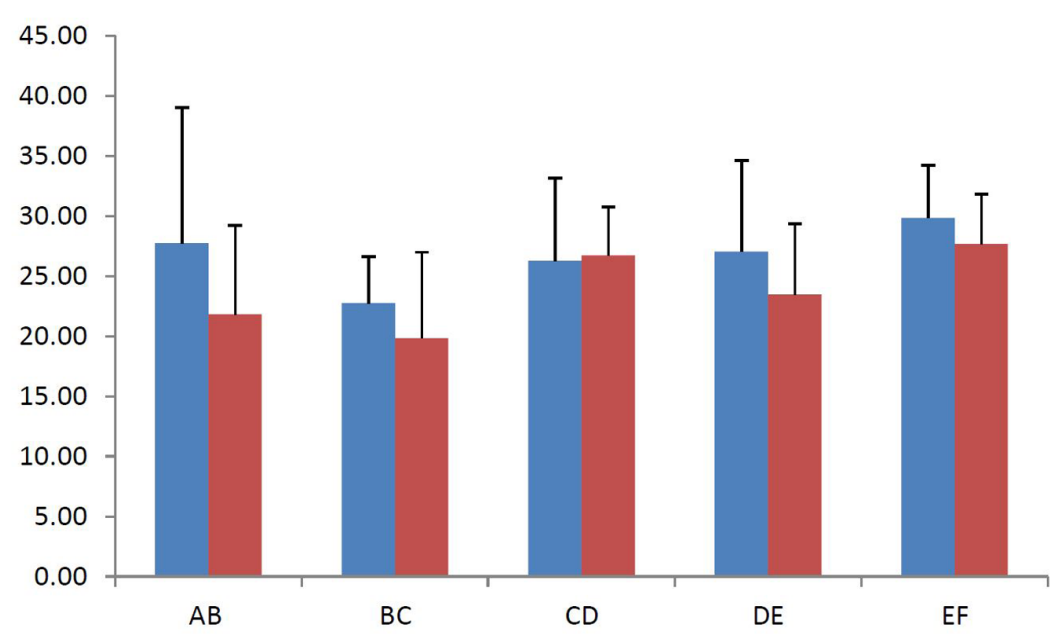

Fig. (6). Normalized jerk. Values are expressed as mean \pm standard deviation. Legend. blue: impaired arm; red: unimpaired arm. $* \mathrm{p}<0.05$.

Different technologies (e.g., wearable sensors, robotic devices, motion recognition systems, motion analysis devices, etc.) have been proposed and validated for posture and physical activity monitoring. Such technologies can be used to detect human movement and to carry out analysis of body motions [38], thus providing accurate and reliable feedback that may also support rehabilitation activities [39].

Recently the miniaturization of devices and the evolution of sensing technologies has produced an increase of the use of wearable sensors (e.g., inertial measurement units, flexible force sensors) for rehabilitation applications: a great variability of systems based on these sensors have been used so far [40]. The analysis of biomechanical parameters computed from physical variables recorded during the rehabilitation training by means of these sensors can be carried out in order to investigate mechanism underlying movement control [41].

Most of these sensors can be considered as an appropriate alternative to motion analysis systems based on cameras and markers which need structured environments and calibration operations that are often laborious and time consuming. Furthermore the costs of the latter are rather high. The device used in this study is portable, easy to use and low-cost.

The parameters proposed in this study can be used to analyse the kinematics (i.e., FMMD, MD, SM, NRS), duration (i.e., FMT) and quality (i.e., NSP and normalized jerk) of upper limb movements following a surgical procedure focused on ACJ reconstruction. In particular our results suggest that goal-directed, planar reaching tasks are appropriate to evaluate shoulder and elbow movements: the movements corresponding to the operated shoulder overlap those recorded on the controlateral side in terms of kinematics, execution time and movement smoothness, and such overlapping highlights the effectiveness of the device and the proposed reaching exercises. As regards the NSP parameter a familiarization mechanism may explain the lower values observed in the impaired arm.

As known in some activities and sports (i.e., biking, fishing) the side dominance does not have a special role. In fact, in two subjects recruited in this pilot study who are used to play such sports and where the dominant side corresponds to the injured side, the functional recovery of the upper limb is complete.

The integration of the CMS and the set of kinematic parameters allow to investigate the subject's upper limb motor abilities by using the operated upper limb in terms of pain, ROM, kinematics, duration and quality.

The integrated approach of clinical outcome measures and kinematic parameter is often used in neuro-rehabilitation field in order to assess the movement quality [20]. Till now the kinematic analysis is often carried out for evaluating the effects of gait rehabilitation by means of expensive motion-capture camera systems [42].

The proposed integrated assessment approach including clinical outcome measures and kinematic parameters may provide useful insights in the orthopaedic field. 


\section{LIMITATIONS OF THE STUDY}

The limitations of this study are represented by the small number of recruited patients and the lack of homogeneity in terms of time elapsed from the surgical procedure.

\section{CONCLUSION}

The results of this pilot study suggest that the motion tracker can be easily used for the quantitative and qualitative assessment of shoulder movements, even several years after the surgical operation.

This pilot study has demonstrated that goal-directed, planar reaching tasks are appropriate to evaluate shoulder and elbow movements following an orthopaedic surgical procedure. The CMS used as clinical outcome measure and the values of seven different kinematic parameters have shown that the differences between the injured and the dominant side are significantly negligible. Indeed no statistically significant changes between the impaired and unimpaired limbs in terms of clinical outcome scale and kinematic parameters were found.

The novelty of this study is represented by the proposal of an assessment method based on the use of a passive motion tracker and seven kinematic parameters following an acromioclavicular joint ligament reconstruction. In addition, our results highlight that a complete upper limb motor recovery occurs even in patients whose impaired limb corresponds to the dominant side.

\section{ETHICS APPROVAL AND CONSENT TO PARTICIPATE}

No approval by the local ethics committee was required, because the study was retrospective.

\section{HUMAN AND ANIMAL RIGHTS}

Animals did not participate in this research. All human research procedures followed were in accordance with the ethical standards of the committee responsible for human experimentation (institutional and national), and with the Helsinki Declaration of 1975, as revised in 2008.

\section{CONSENT FOR PUBLICATION}

Informed consent was obtained from all the participants.

\section{CONFLICT OF INTEREST}

The authors declare no conflict of interest, financial or otherwise.

\section{ACKNOWLEDGEMENTS}

The authors wish to express their gratitude to Humanware Srl (Pisa, Italy) for its technical support and valuable collaboration.

\section{REFERENCES}

[1] A.H. Crenshaw, "Fractures of the shoulder girdle, arm and forearm", In: Campbell's operative orthopaedics. $8^{\text {th }}$ ed, A.H. Crenshaw, St. Louis: Mosby; 1992, pp. 989-1053.

[2] A. Babhulkar, and A. Pawaskar, "Acromioclavicular joint dislocations", Curr. Rev. Musculoskelet. Med., vol. 7, no. 1, pp. 33-39, 2014. [http://dx.doi.org/10.1007/s12178-013-9199-2] [PMID: 24431027]

[3] C. Ulucay, T. Ozler, B. Akman, B. Aksu, F. Altintas, and M.N. Doral, "Treatment of acromioclavicular joint injuries in athletes and in young active", J. Trauma Treat., vol. 5, p. 344, 2016. [http://dx.doi.org/10.4172/2167-1222.1000344]

[4] C.A. Rockwood, G.R. Williams, and C.D. Young, "Injuries to the acromionclavicular joint", In: Fractures in adults., Rockwood CA Jr et al. (eds), Lippincott-Raven: Philadelphia, 1996, pp. 1341-1431.

[5] A. De Carli, R.M. Lanzetti, A. Ciompi, D. Lupariello, P. Rota, and A. Ferretti, "Acromioclavicular third degree dislocation: Surgical treatment in acute cases", J. Orthop. Surg. Res., vol. 10, p. 13, 2015. [http://dx.doi.org/10.1186/s13018-014-0150-z] [PMID: 25627466]

[6] M. Tauber, "Management of acute acromioclavicular joint dislocations: Current concepts", Arch. Orthop. Trauma Surg., vol. 133, no. 7, pp. 985-995, 2013. [http://dx.doi.org/10.1007/s00402-013-1748-z] [PMID: 23632779]

[7] A.D. Mazzocca, R.A. Arciero, and J. Bicos, "Evaluation and treatment of acromioclavicular joint injuries", Am. J. Sports Med., vol. 35, no. 2, 
pp. 316-329, 2007.

[http://dx.doi.org/10.1177/0363546506298022] [PMID: 17251175]

[8] E. Ceccarelli, R. Bondì, F. Alviti, R. Garofalo, F. Miulli, and R. Padua, "Treatment of acute grade III acromioclavicular dislocation: A lack of evidence", J. Orthop. Traumatol., vol. 9, no. 2, pp. 105-108, 2008. [http://dx.doi.org/10.1007/s10195-008-0013-7] [PMID: 19384625]

[9] A.M. Phillips, C. Smart, and A.F. Groom, "Acromioclavicular dislocation. Conservative or surgical therapy", Clin. Orthop. Relat. Res., no. 353, pp. 10-17, 1998.

[http://dx.doi.org/10.1097/00003086-199808000-00003] [PMID: 9728155]

[10] T.O. Smith, R. Chester, E.O. Pearse, and C.B. Hing, "Operative versus non-operative management following Rockwood grade III acromioclavicular separation: A meta-analysis of the current evidence base", J. Orthop. Traumatol., vol. 12, no. 1, pp. 19-27, 2011. [http://dx.doi.org/10.1007/s10195-011-0127-1] [PMID: 21344264]

[11] K. Beitzel, M.P. Cote, J. Apostolakos, O. Solovyova, C.H. Judson, C.G. Ziegler, C.M. Edgar, A.B. Imhoff, R.A. Arciero, and A.D. Mazzocca, "Current concepts in the treatment of acromioclavicular joint dislocations", Arthroscopy, vol. 29, no. 2, pp. $387-397,2013$. [http://dx.doi.org/10.1016/j.arthro.2012.11.023] [PMID: 23369483]

[12] G. Fraschini, P. Ciampi, C. Scotti, R. Ballis, and G.M. Peretti, "Surgical treatment of chronic acromioclavicular dislocation: Comparison between two surgical procedures for anatomic reconstruction", Injury, vol. 41, no. 11, pp. 1103-1106, 2010. [http://dx.doi.org/10.1016/j.injury.2010.09.023] [PMID: 20934695]

[13] R. Riener, T. Nef, and G. Colombo, "Robot-aided neurorehabilitation of the upper extremities", Med. Biol. Eng. Comput., vol. 43, no. 1, pp. $2-10,2005$. [http://dx.doi.org/10.1007/BF02345116] [PMID: 15742713]

[14] N. Garcia, J.M. Sabater-Navarro, E. Gugliemeli, and A. Casals, "Trends in rehabilitation robotics", Med. Biol. Eng. Comput., vol. 49, no. 10, pp. 1089-1091, 2011. [http://dx.doi.org/10.1007/s11517-011-0836-x] [PMID: 21959593]

[15] Z.Q. Zhang, W.C. Wong, and J.K. Wu, "Ubiquitous human upper-limb motion estimation using wearable sensors", IEEE Trans. Inf. Technol. Biomed., vol. 15, no. 4, pp. 513-521, 2011.

[http://dx.doi.org/10.1109/TITB.2011.2159122] [PMID: 21659035]

[16] L. Zollo, L. Rossini, M. Bravi, G. Magrone, S. Sterzi, and E. Guglielmelli, "Quantitative evaluation of upper-limb motor control in robotaided rehabilitation", Med. Biol. Eng. Comput., vol. 49, no. 10, pp. 1131-1144, 2011. [http://dx.doi.org/10.1007/s11517-011-0808-1] [PMID: 21792622]

[17] R. Colombo, I. Sterpi, A. Mazzone, C. Delconte, G. Minuco, and F. Pisano, "Measuring changes of movement dynamics during robot-aided neurorehabilitation of stroke patients", IEEE Trans. Neural Syst. Rehabil. Eng., vol. 18, no. 1, pp. 75-85, 2010. [http://dx.doi.org/10.1109/TNSRE.2009.2028831] [PMID: 19666344]

[18] S. Mazzoleni, F. Posteraro, M. Filippi, F. Forte, S. Micera, P. Dario, and M.C. Carrozza, "Biomechanical assessment of reaching movements in post-stroke patients during a robot-aided rehabilitation", Appl. Bionics Biomech., vol. 8, pp. 39-54, 2011. [http://dx.doi.org/10.1155/2011/298926]

[19] S. Balasubramanian, R. Colombo, I. Sterpi, V. Sanguineti, and E. Burdet, "Robotic assessment of upper limb motor function after stroke", Am. J. Phys. Med. Rehabil., vol. 91, no. 11, suppl. Suppl. 3, pp. S255-S269, 2012. [http://dx.doi.org/10.1097/PHM.0b013e31826bcdc1] [PMID: 23080041]

[20] N. Nordin, S.Q. Xie, and B. Wünsche, "Assessment of movement quality in robot- assisted upper limb rehabilitation after stroke: A review", J. Neuroeng. Rehabil., vol. 11, no. 137, p. 137, 2014. [http://dx.doi.org/10.1186/1743-0003-11-137] [PMID: 25217124]

[21] C. Duret, O. Courtial, and A.G. Grosmaire, "Kinematic measures for upper limb motor assessment during robot-mediated training in patients with severe sub-acute stroke", Restor. Neurol. Neurosci., vol. 34, no. 2, pp. 237-245, 2016. [http://dx.doi.org/10.3233/RNN-150565] [PMID: 26890098]

[22] C. Shirota, J. Jansa, J. Diaz, S. Balasubramanian, S. Mazzoleni, N.A. Borghese, and A. Melendez-Calderon, "On the assessment of coordination between upper extremities: Towards a common language between rehabilitation engineers, clinicians and neuroscientists", $J$. Neuroeng. Rehabil., vol. 13, no. 1, p. 80, 2016.

[http://dx.doi.org/10.1186/s12984-016-0186-x] [PMID: 27608923]

[23] A. de los Reyes-Guzmán, I. Dimbwadyo-Terrer, F. Trincado-Alonso, F. Monasterio-Huelin, D. Torricelli, and A. Gil-Agudo, "Quantitative assessment based on kinematic measures of functional impairments during upper extremity movements: A review", Clin. Biomech. (Bristol, Avon), vol. 29, no. 7, pp. 719-727, 2014

[http://dx.doi.org/10.1016/j.clinbiomech.2014.06.013] [PMID: 25017296]

[24] W.Y. Wong, M.S. Wong, and K.H. Lo, "Clinical applications of sensors for human posture and movement analysis: A review", Prosthet. Orthot. Int., vol. 31, no. 1, pp. 62-75, 2007. [http://dx.doi.org/10.1080/03093640600983949] [PMID: 17365886]

[25] A.G. Cutti, and E.K. Chadwick, "Shoulder biomechanics and the success of translational research", Med. Biol. Eng. Comput., vol. 52, no. 3, pp. 205-210, 2014. [http://dx.doi.org/10.1007/s11517-014-1143-0] [PMID: 24567068] 
[26] J. Cholewicki, M.M. Panjabi, and A. Khachatryan, "Stabilizing function of trunk flexor-extensor muscles around a neutral spine posture", Spine, vol. 22, no. 19, pp. 2207-2212, 1997. [http://dx.doi.org/10.1097/00007632-199710010-00003] [PMID: 9346140]

[27] G.A. Hansson, P. Asterland, N.G. Holmer, and S. Skerfving, "Validity and reliability of triaxial accelerometers for inclinometry in posture analysis", Med. Biol. Eng. Comput., vol. 39, no. 4, pp. 405-413, 2001. [http://dx.doi.org/10.1007/BF02345361] [PMID: 11523728]

[28] H.J. Luinge, and P.H. Veltink, "Measuring orientation of human body segments using miniature gyroscopes and accelerometers", Med. Biol. Eng. Comput., vol. 43, no. 2, pp. 273-282, 2005.

[http://dx.doi.org/10.1007/BF02345966] [PMID: 15865139]

[29] A.G. Cutti, A. Giovanardi, L. Rocchi, A. Davalli, and R. Sacchetti, "Ambulatory measurement of shoulder and elbow kinematics through inertial and magnetic sensors", Med. Biol. Eng. Comput., vol. 46, no. 2, pp. 169-178, 2008. [http://dx.doi.org/10.1007/s11517-007-0296-5] [PMID: 18087742]

[30] C.R. Constant, and A.H.G. Murley, "A clinical method of functional assessment of the shoulder", Clin. Orthop. Relat. Res., no. 214, pp. 160-164, 1987. [PMID: 3791738$]$

[31] V.B. Conboy, R.W. Morris, J. Kiss, and A.J. Carr, "An evaluation of the Constant-Murley shoulder assessment", J. Bone Joint Surg. Br., vol. 78, no. 2, pp. 229-232, 1996. [http://dx.doi.org/10.1302/0301-620X.78B2.0780229] [PMID: 8666631]

[32] M.T. Hirschmann, B. Wind, F. Amsler, and T. Gross, "Reliability of shoulder abduction strength measure for the Constant-Murley score", Clin. Orthop. Relat. Res., vol. 468, no. 6, pp. 1565-1571, 2010 [http://dx.doi.org/10.1007/s11999-009-1007-3] [PMID: 19639370]

[33] R. Magatsari, "Sensitiveness of the Constant-Murley's Shoulder and quick DASH as an outcome measure for mid shaft clavicle fracture", Malays. Orthop. J., vol. 4, pp. 4-7, 2010. [http://dx.doi.org/10.5704/MOJ.1003.001]

[34] S. Mazzoleni, P. Sale, M. Tiboni, M. Franceschini, M.C. Carrozza, and F. Posteraro, "Upper limb robot-assisted therapy in chronic and subacute stroke patients: A kinematic analysis", Am. J. Phys. Med. Rehabil., vol. 92, no. 10, suppl. Suppl. 2, pp. e26-e37, 2013. [http://dx.doi.org/10.1097/PHM.0b013e3182a1e852] [PMID: 24052027]

[35] B. Rohrer, S. Fasoli, H.I. Krebs, R. Hughes, B. Volpe, W.R. Frontera, J. Stein, and N. Hogan, "Movement smoothness changes during stroke recovery", J. Neurosci., vol. 22, no. 18, pp. 8297-8304, 2002. [http://dx.doi.org/10.1523/JNEUROSCI.22-18-08297.2002] [PMID: 12223584]

[36] N. Hogan, and D. Sternad, "Sensitivity of smoothness measures to movement duration, amplitude, and arrests", J. Mot. Behav., vol. 41, no. 6, pp. 529-534, 2009.

[http://dx.doi.org/10.3200/35-09-004-RC] [PMID: 19892658]

[37] H.L. Teulings, J.L. Contreras-Vidal, G.E. Stelmach, and C.H. Adler, "Parkinsonism reduces coordination of fingers, wrist, and arm in fine motor control", Exp. Neurol., vol. 146, no. 1, pp. 159-170, 1997. [http://dx.doi.org/10.1006/exnr.1997.6507] [PMID: 9225749]

[38] S.C. Mukhopadhaya, "Wearable sensors for human activity monitoring: A review", IEEE Sens. J., vol. 15, pp. 1321-1330, 2015. [http://dx.doi.org/10.1109/JSEN.2014.2370945]

[39] A.A. Timmermans, H.A. Seelen, R.D. Willmann, and H. Kingma, "Technology-assisted training of arm-hand skills in stroke: Concepts on reacquisition of motor control and therapist guidelines for rehabilitation technology design", J. Neuroeng. Rehabil., vol. 6, pp. 1-18, 2009. [http://dx.doi.org/10.1186/1743-0003-6-1] [PMID: 19154570]

[40] Q. Wang, P. Markopoulos, B. Yu, W. Chen, and A. Timmermans, "Interactive wearable systems for upper body rehabilitation: A systematic review", J. Neuroeng. Rehabil., vol. 14, no. 1, p. 20, 2017. [http://dx.doi.org/10.1186/s12984-017-0229-y] [PMID: 28284228]

[41] I. Parel, E. Jaspers, L. DE Baets, A. Amoresano, and A.G. Cutti, "Motion analysis of the shoulder in adults: Kinematics and electromyography for the clinical practice", Eur. J. Phys. Rehabil. Med., vol. 52, no. 4, pp. 575-582, 2016. [PMID: 27434612]

[42] H. Alradwan, M. Khan, M.H. Grassby, A. Bedi, M.J. Philippon, and O.R. Ayeni, "Gait and lower extremity kinematic analysis as an outcome measure after femoroacetabular impingement surgery", Arthroscopy, vol. 31, no. 2, pp. 339-344, 2015. [http://dx.doi.org/10.1016/j.arthro.2014.06.016] [PMID: 25129866]

(C) 2018 Mazzoleni et al.

This is an open access article distributed under the terms of the Creative Commons Attribution 4.0 International Public License (CC-BY 4.0), a copy of which is available at: https://creativecommons.org/licenses/by/4.0/legalcode. This license permits unrestricted use, distribution, and reproduction in any medium, provided the original author and source are credited. 